\title{
BMJ Open Associations between physical function and depression in nursing home residents with mild and moderate dementia: a cross-sectional study
}

\author{
Linda Aimée Hartford Kvæl, ${ }^{1,2}$ Astrid Bergland, ${ }^{1}$ Elisabeth Wiken Telenius ${ }^{1,3}$
}

To cite: Kvæl LAH, Bergland A, Telenius EW. Associations between physical function and depression in nursing home residents with mild and moderate dementia: a crosssectional study. BMJ Open 2017;7:e016875. doi:10.1136/ bmjopen-2017-016875

- Prepublication history for this paper is available online. To view these files please visit the journal online (http://dx.doi org/10.1136/bmjopen-2017016875).

Received 16 March 2017 Revised 19 May 2017 Accepted 24 May 2017

\section{CrossMark}

${ }^{1}$ Department of Physiotherapy, Faculty of Health Sciences, Oslo and Akershus University College of Applied Sciences, Oslo,

Norway

${ }^{2}$ Ryen Helsehus/Short-term Rehabilitation, Nursing Home Agency, Oslo, Norway

${ }^{3}$ Norwegian National Advisory Unit on Ageing and Health, Vestfold Hospital Trust, Tønsberg, Norway

Correspondence to Linda Aimée Hartford Kvæl; lindaeriksen@hotmail.com

\section{ABSTRACT}

Objectives The primary aim of this study is to describe depression and physical function in nursing home residents with dementia, as well as to examine the associations between depression and balance function, lower limb muscle strength, mobility and activities of daily living. The secondary aim is to examine the differences in physical function between the groups classified as depressed and not depressed.

Design The study has a cross-sectional design.

Setting A convenience sample of 18 nursing homes in, and around, 0slo, Norway, participated.

Participants We included 170 nursing home residents aged 60-100 years with mild or moderate degree of dementia defined by a score of 1 or 2 on the Clinical Dementia Rating Scale (CDR).

Outcome measures Assessments used were Cornell Scale for Depression in Dementia (CSDD), Berg Balance Scale (BBS), 'the 6-metre walking test' (walking speed), $30 \mathrm{~s}$ Chair Stand Test (CST) and the Barthel Index (BI). Results Nursing home residents with dementia are a heterogeneous group in terms of physical function and depression. By applying the recommended cut-off of $\geq 8$ on CSDD, $23.5 \%$ of the participants were classified as being depressed. The results revealed significant associations between higher scores on CSDD (indicating more symptoms of depression) and lower scores on BBS $(95 \% \mathrm{Cl}$ -0.12 to $-0.02, p=0.006), 30$ s CST $(95 \% \mathrm{Cl}-0.54$ to $-0.07, p=0.001$ ) as well as maximum walking speed $(95 \% \mathrm{Cl}-4.56$ to $-0.20, p=0.003)$ (indicating lower level of physical function).

Conclusion Better muscle strength, balance and higher walking speed were significantly associated with less depressive symptoms. The potential interaction of dementia with poor physical function and depression indicates an area to explore in future epidemiological studies with a prospective design.

Trial registration number NCT02262104.

\section{INTRODUCTION}

Dementia impact has received increasing attention of governments and politicians across the world in recent years. Societies globally face an increasing proportion of older people who, by reason of age alone, are at increasing risk of dementia. ${ }^{1}$ On
Strengths and limitations of this study

- This study reports important information about the associations between physical function, assessed by performance-based tests, and depression in nursing home residents with dementia

- The study included a well-defined population of older nursing home residents with mild and moderate dementia defined by score of 1 or 2 on the Clinical Dementia Rating Scale

- Measuring instruments employed in this study are standardised and commonly used in clinical practice among frail elderly in nursing homes

- The participants were enrolled in a physical exercise intervention trial (EXDEM), so they were likely to be fitter than the average nursing home population

- Because of the cross-sectional design of the study, we cannot draw conclusions about causality

an international level, the prevalence of dementia among older adults in long-term care homes has a median of $58 \%,{ }^{2}$ but the underdiagnosis of dementia in nursing homes is commonly reported in literature worldwide. ${ }^{3-5}$ Approximately $80 \%$ of people living in nursing homes in Norway have dementia. ${ }^{6}$ The prevalence of depressive disorders among nursing home residents is $10 \%$, while the prevalence of depressive symptoms is $29 \%$ on an international level. ${ }^{2}$ Depression is frequently occurring in nursing home residents with dementia $(43 \%)^{7}$ and is associated with reduced quality of life, ${ }^{8}$ poor medical health and more severe cognitive impairment. ${ }^{9}$ WHO defines depression as 'a mental disorder, characterised by sadness, loss of interest or pleasure, feelings of guilt or low self-worth, disturbed sleep or appetite, feelings of tiredness and poor concentration. ${ }^{10}$ Reduced physical function and dependency in old age as well as somatic disorders are the main risk factors for developing depression..$^{911}$ Loneliness and lack of social support are 
other risk factors. ${ }^{12} 13$ Depression is a multifactorial concept and results from a complex interaction of social, psychological and biological factors. ${ }^{14}$ According to $\mathrm{WHO}$, there are interrelationships between depression and physical health. ${ }^{15}$

Among elderly people in general, better physical function is associated with lower incidence of depressive symptoms. ${ }^{16}{ }^{17}$ It is also related to better mental health, quality of life and well-being. ${ }^{18}{ }^{19}$ Despite recommendations of regular physical activity, research shows that nursing home residents are spending most of their time seated or lying down, even when they are capable of independent or assisted activity. ${ }^{20}$ It is alarming that residents who are capable of performing activities of daily living (ADL) independently or with assistance often do not get the opportunity to participate actively, especially since physical function is a modifiable factor reliant on the continuous use of the musculoskeletal system. ${ }^{21}$

It is well known that physical function is modifiable through exercise. Even though the importance of physical activity for the preservation of function in elderly is well documented, ${ }^{21-28}$ the relationship between physical function and depression in nursing home residents with dementia is unclear, and results from studies are ambiguous. Some studies indicate that nursing home residents with good physical function are less depressed than those with low level of physical function, ${ }^{829}$ while others do not find any significant associations between the two factors. ${ }^{9}$

Studies that have investigated the relationship between physical function and depression in persons with dementia in nursing homes have largely employed proxy-reported measures of physical function and not performance-based tests. Performance-based tests are more sensitive than self-reported or proxy-reported measures of physical function and may be better to identify the true abilities of an individual. ${ }^{30}$ The relationship between physical function, tested with performance-based tests, and depression in nursing home residents with dementia seems to constitute a provisional 'gap' in knowledge. The topic is important because depression in nursing home residents with dementia is common, ${ }^{31}{ }^{32}$ and good alternatives to psychotropic drugs are called for. ${ }^{32-34}$

It is important to identify modifiable factors underlying or associated with depression in the growing population of nursing home residents with dementia. Therefore, the primary aim of this study was to describe physical function and depression in this population, as well as to examine the associations between depression and levels of balance, muscle strength, mobility and daily life activity. The secondary aim was to examine differences in physical function between the group classified as depressed and not depressed. Although the authors have an assumption that there is a negative relationship between depression and physical function, the study is explorative and thus no hypotheses are tested.
METHODS

\section{Design}

The study has a cross-sectional design. The data were collected from baseline measurements of a randomised controlled trial (RCT) (EXDEM) that was carried out in Norway in 2012 and 2013.

\section{Setting and participants}

A convenience sample of 18 nursing homes in Oslo, as well as in the counties of Akershus, Oppegård and Buskerud, participated. We included 170 nursing home residents. The inclusion criteria were the following: mild or moderate degree of dementia (defined by a score of 1 or 2 on the Clinical Dementia Rating Scale), ${ }^{35}$ age above 55 years, able to stand up independently or with help from one person, able to walk 6 metres with or without a walking aid and able to give informed consent. The exclusion criteria were the following: residents with psychosis or severe communication problems and residents who were medically unstable. The nursing home employees at participating nursing homes found suitable participants, between 6 and 12 persons at each nursing home. A total of 182 persons agreed to participate in the study; however, 8 changed their mind prior to first assessment and 4 participants were excluded because the inclusion criteria were not met.

\section{Ethical and legal considerations}

Verbal and written information about the study was given to the residents and their family members by their primary caregiver. The participants themselves gave their written consent to participate in the study and were informed that they could refuse to participate at any stage. The Regional Committee for Medical Ethics in south east of Norway approved the RCT study.

\section{Measurements}

Depression

Depression was measured with Cornell Scale for Depression in Dementia (CSDD), a proxy-rated scale. ${ }^{36}$ The informants were caregivers who knew the resident well and had observed the residents for the last 2 weeks. ${ }^{37}$ CSDD is valid among nursing home residents with and without dementia, and the reliability is good (Cronbach's $\alpha$ values were 0.81 and 0.95$).{ }^{38}$ The questionnaire consists of 19 symptom items. Each item is rated from 0 (no symptom) to 2 (severe symptom), which gives a total range of 0-38 points. The scale allows the entry "not possible to evaluate. ${ }^{36} \mathrm{~A}$ score of 8 or more on CSDD classified those with depression. ${ }^{38}$

\section{Balance}

To measure the residents' balance, we employed the Berg Balance Scale (BBS), a widely used performance-based measure of balance. BBS consists of 14 observable tasks frequently encountered in everyday life. BBS assesses performance on a five-level scale from 0 (cannot perform) to 4 (normal performance) on 14 different movement tasks involving functional balance control, including 
transfer, stepping and turning. ${ }^{39}$ The test is simple and easy to administer and is safe for the elderly to perform. ${ }^{40}$ The total score ranges from 0 to 56 , and high score indicates good balance. ${ }^{41}$ The scale has shown good intrarater and inter-rater reliability when used with an elderly population in Norway (Cronbach's $\alpha$ values were 0.87 and $0.9) .{ }^{42}{ }^{43}$ In addition, acceptable validity estimates have been reported. ${ }^{44}$

\section{Muscle strength}

Lower limb muscle strength was measured by the $30 \mathrm{~s}$ Chair Stand Test (CST), which equals the number of rises from the chair in $30 \mathrm{~s}$ with arms folded across the chest. ${ }^{45}$ However, in this study the participants were allowed to use the support of armrest when necessary. ${ }^{46}$ The test correlates well with other functional tests such as walking speed, climbing stairs and balance. ${ }^{40} 47$ The $30 \mathrm{~s}$ CST is a valid measure of dynamic balance and functional mobility, ${ }^{48}$ and good inter-rater reliability has been reported when used among nursing home residents with mild and moderate dementia (the intraclass correlation coefficient (ICC) was 1 ). ${ }^{43}$

\section{Mobility}

Mobility/walking speed was measured by the $6 \mathrm{~m}$ walking test. We assessed both comfortable and maximum walking speed, with or without a walking aid, and the time in seconds was recorded and calculated as metres per second. ${ }^{49}$ Good inter-rater reliability has been demonstrated when used among nursing home residents with mild and moderate dementia in Norway (ICC=0.97). ${ }^{43}$ Walking speed is regarded as an important measure in geriatric evaluation. ${ }^{50}$

\section{Activities of daily living}

The Barthel Index (BI) was used to assess ability to perform the basic ADL, a widely used measure of ADL function. ${ }^{51}$ BI consists of 10 activities focusing on the residents' level of dependence, and the scores range from 0 (completely dependent) to 20 (independent). ${ }^{52}$ The maximum score of 20 implies that the resident independently can attend to personal hygiene, eat, get dressed, go to the bathroom, walk at least $50 \mathrm{~m}$ and use stairs.

\section{Cognition}

Clinical Dementia Rating Scale (CDR) was used to rate the severity of cognitive impairment. It is a six-point scale used to characterise domains of cognitive and functional performance applicable to Alzheimer's disease and related dementias. ${ }^{35}$ Norwegian studies have shown that CDR Scale is a valid substitute for dementia assessment among nursing home residents to rate dementia and dementia severity. ${ }^{53}$ The Norwegian version of Mini Mental State Examination (MMSE-NR) was used to assess global cognition. MMSE-NR consists of items concerning orientation, word registration and recall, attention, naming, reading, writing, following commends and figure copying. It can be scored between 0 and 30 . High score indicates better performance. ${ }^{55}{ }^{56} \mathrm{CDR}$ is thus a measure to rate dementia and dementia severity, while Mini Mental State Examination (MMSE) assesses global cognition. As the dementia severity increases, the global cognition performance reduces.

\section{Demographic factors}

Participants' age and gender, length of stay in a nursing home (from date of admission), number of drugs, number of chronic disorders (musculoskeletal, neurological, cardiovascular and psychiatric diagnoses), use of walking aids and the residents' ability to rise from chair independently were registered. Demographic factors were extracted from the residents' journals.

\section{Procedure}

A nurse, and often the departmental nurse, who knew the participants well and was in regular contact with him/ her, performed CDR and filled in the Case Record Form. Mostly, nursing staff was familiar with the questionnaires. However, they were encouraged to contact the project leader with any questions. A specially trained nurse or an occupational therapist performed MMSE. Research physiotherapists performed all assessments of physical function. To ensure high inter-rater test reliability, the testers took part in a training programme on testing procedures before the study was initiated. Nursing home staff who knew the participants well filled out the proxy assessments, including CSDD and BI. Primary caregivers extracted information from the resident records.

\section{Statistics}

All statistical analyses were conducted with SPSS (Statistical Package for the Social Science) V.22 for Windows. Data are presented with percentages and proportions for categorical values and means with standard deviation (SD) for interval data. The t-test was applied for interval data, and the $\chi^{2}$ test was applied for categorical data to access statistical differences between groups. Correlation analyses (Pearson's r) were conducted to examine the associations between the variables of physical function in order to discover multicollinearity.

Linear regression analyses were applied to explore bivariate and multivariate associations between Cornell Scale score and the independent variables. Each of the univariate regression models was examined separately to make sure the conditions for linear regression analysis existed. We analysed linearity, homoscedasticity and the normal distribution of the residuals by inspecting normal probability plots, different scatterplots and histograms. ${ }^{57}$ Extreme values were examined in line with outliers labelling technique ${ }^{58}$ We identified one extreme value based on the Cornell sum score, two based on maximum walking speed and one based on comfortable walking speed. However, according to Pallant, ${ }^{57}$ it is not necessary to correct for these as long as the numbers are few and the group is large enough. We considered the group to be large $(n=170)$ and have therefore not adjusted for these in the further analyses. ${ }^{57}$ From the 
unadjusted linear regression analyses, we selected variables having the strongest association with the outcome $(p<0.05)$ and fitted multiple linear regression models in addition to the variables of age and gender. Three different multiple linear regression models were fitted because of high correlation (multicollinearity) between the variables of physical performance. BBS was included in the first model, CST was included in the second model and maximum walking speed was included in the third model. This measure was taken to identify a model that explained the largest proportion of the variance in the Cornell Scale. To compare the strength of the associations between the various possible predictors and the main outcome (Cornell Scale), we used the standardised betas from the regression models with their $\mathrm{p}$ values and the adjusted coefficient of determination (R2).

CSDD is commonly used in nursing homes to distinguish between groups of depressed and not depressed. This is important in the detection and treatment of depression in persons with dementia. Because of this clinical relevance, we found it necessary to perform logistic regression analysis to see if the results from logistic regression analysis differed significantly from the results of linear regression analysis. The odds ratio (OR), based on logistic regression analysis, showed the strength of association between the groups with and without depression and physical function. A score of 8 or more on CSDD classified the participants with depression. ${ }^{38}$ Two multiple logistic regression models were fitted because of multicollinearity $(r=0.7)$ between BBS and CST. In the first model, BBS was included, and in the second model, we included CST, in addition to age and gender. The level of statistical significance was set at $\mathrm{p}<0.05$ in all analyses, and all tests were two tailed.

\section{RESULTS}

\section{Sample characteristics}

Characteristics for whole sample, depressed and not depressed participants are shown in table 1 . Of the 170 nursing home residents with dementia, $73.5 \%$ were woman with a mean age of 88.2 years. The mean duration of stay in nursing home for the whole sample was 2 years and 2 months; the depressed participants' stay were approximately 4 months longer.

About $50 \%$ of the participants were diagnosed with a cardiovascular disease, and one in five $(n=34)$ had a psychiatric diagnosis (anxiety, depression, bipolar disorder) where the most common were anxiety and depression. Furthermore, approximately $40 \%$ were diagnosed with a musculoskeletal diagnosis and almost one in four had a neurological condition. The depressed participants had significantly more psychiatric diagnoses than the not depressed $(\mathrm{p}=0.02)$. Approximately $10 \%$ of the nursing home residents with dementia used a wheelchair, and $50 \%$ used a Zimmer frame.

\section{Cognition}

Regarding cognition, the participants' scores on MMSE ranged from 2 to 28 points. A total of $88.7 \%$ of the participants' MMSE scores fell within mild and moderate dementia (10-26 points), ${ }^{59} 16(10.9 \%)$ scored less than 10 points (indicating severe dementia) and $1.4 \%$ scored higher than 26 points. Only 56\% (n=95) of the participants had a pre-existing dementia diagnosis; 23 were diagnosed with Alzheimer's disease, 18 with vascular dementia, 1 with subcortical dementia and 1 with frontotemporal dementia. A group of 52 participants did not have a specific diagnosis but had dementia according to medical records.

\section{Depression}

The score on CSDD ranged from $0 \quad(n=20)$ to $21 \quad(n=1)$ points. The mean value for the whole sample was 4.9 points, and no significant gender difference was observed regarding CSDD $(p=0.45)$. By applying the recommended cut-off of $\geq 8$ on CSDD, ${ }^{38} 23.5 \% \quad(n=38)$ of the participants were classified as being depressed, and 29 (76.3\%) of them were women. Only 13 participants in the depressed group had a pre-existing clinical diagnosis of mood disorder compared with 20 participants in the non-depressed group. The participants classified as not depressed were significantly better to rise from chair independently $(\mathrm{p}=0.04)$. The number of chronic diseases ranged between 0 and 11, the mean number was 3.4 diagnoses $(\mathrm{SD}=1.9)$ and the average number of medications was $6.4(\mathrm{SD}=3.4)$. There was a statistical trend $(\mathrm{p}<0.10)$ where participants classified as depressed had more diagnoses and used more medications than the participants in the group without depression.

\section{Physical function}

Regarding the physical performance assessments, the mean values of the tests and SD are shown in table 1 . The mean score on BBS was 34.7 for the whole sample, and the scores ranged from 3 to 56 points. On average, the participants were able to stand up six times in $30 \mathrm{~s}$ and mean maximum walking speed was $0.8 \mathrm{~m} / \mathrm{s}$. The participants classified as depressed had significantly lower score on BBS ( $p=0.03$ ) and 30 s Chair Stand Test $(p=0.02)$, indicating poorer balance function and lower limb strength compared with those without depression (table 1). The associations between the different variables of physical function are shown in table 2. The highest correlation was found between BBS, CST and maximum walking speed, which had consequences for the further analyses (see statistics).

\section{Association between physical performance and level of depression}

The unadjusted and adjusted linear regression analyses showed a significant relationship between depressive symptoms (CSDD score) and physical function for the variables measuring balance (BBS), muscle strength (CST) and maximum walking speed. Higher scores on 


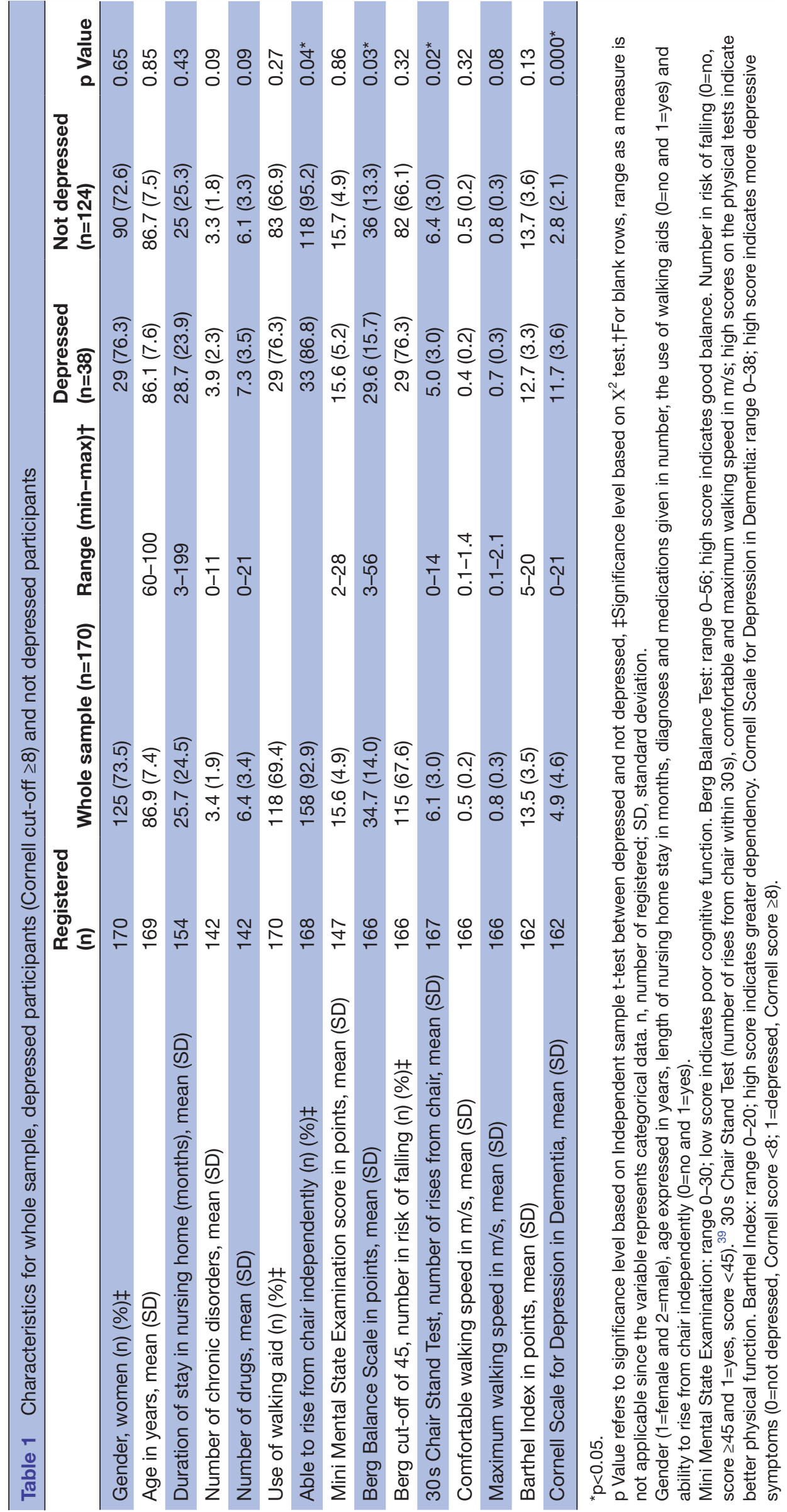


Table 2 Correlations between the different physical function measures and CSDD (the Pearson's correlation coefficients)

\begin{tabular}{|c|c|c|c|c|c|}
\hline & $\begin{array}{l}\text { Berg Balance Test } \\
(n=166)\end{array}$ & $\begin{array}{l}\text { Chair } \\
\text { Stand Test }(n=167)\end{array}$ & $\begin{array}{l}\text { Comfortable walking } \\
\text { speed }(n=166)\end{array}$ & $\begin{array}{l}\text { Maximum walking } \\
\text { speed }(n=166)\end{array}$ & $\begin{array}{l}\text { Barthel ADL } \\
\text { Index }(n=162)\end{array}$ \\
\hline $\begin{array}{l}\text { Chair Stand Test } \\
(n=167)\end{array}$ & $\begin{array}{l}0.7 \\
(p<0.01)\end{array}$ & & & & \\
\hline $\begin{array}{l}\text { Comfortable walking } \\
\text { speed }(n=166)\end{array}$ & $\begin{array}{l}0.6 \\
(p<0.01)\end{array}$ & $\begin{array}{l}0.7 \\
(p<0.01)\end{array}$ & & & \\
\hline $\begin{array}{l}\text { Maximum walking } \\
\text { speed }(n=166)\end{array}$ & $\begin{array}{l}0.7 \\
(p<0.01)\end{array}$ & $\begin{array}{l}0.7 \\
(p<0.01)\end{array}$ & $\begin{array}{l}0.8 \\
(p<0.01)\end{array}$ & & \\
\hline $\begin{array}{l}\text { Barthel ADL Index } \\
(n=162)\end{array}$ & $\begin{array}{l}0.7 \\
(p<0.01)\end{array}$ & $\begin{array}{l}0.6 \\
(p<0.01)\end{array}$ & $\begin{array}{l}0.5 \\
(p<0.01)\end{array}$ & $\begin{array}{l}0.6 \\
(p<0.01)\end{array}$ & \\
\hline $\begin{array}{l}\text { Cornell Scale for } \\
\text { Depression }(n=162)\end{array}$ & $\begin{array}{l}-0.2 \\
(p<0.01)\end{array}$ & $\begin{array}{l}-0.2 \\
(p=0.01)\end{array}$ & $\begin{array}{l}-0.12 \\
(p=0.12)\end{array}$ & $\begin{array}{l}-0.2 \\
(p=0.03)\end{array}$ & $\begin{array}{l}-0.13 \\
(p=0.12)\end{array}$ \\
\hline
\end{tabular}

$A D L$, activities of daily living.

CST, BBS and maximum walking speed were associated with less depressive symptoms (table 3).

Furthermore, the unadjusted linear regression analyses provided a statistical trend $(\mathrm{p}<0.10)$ for the association between greater severity of depressive symptoms (Cornell) and more chronic diseases $(\mathrm{p}=0.09)$ as well as less ability to rise from chair independently $(\mathrm{p}=0.07)$.

\section{Associations between physical function and being depressed or not being depressed}

The unadjusted and adjusted logistic regression analyses revealed significant differences between the groups classified as depressed (Cornell $\geq 8$ ) and not depressed in terms of the variables measuring balance (BBS) and muscle strength (CST). High scores on the physical tests reduced the likelihood of being depressed. A 1-unit increase in sum score on BBS decreased OR by $3.2 \%$ and 1 increase in number of rises on CST decreased OR by $15.2 \%$ for being classified as depressed adjusted for gender and age (table 4).

Furthermore, the unadjusted logistic regression analysis provided a statistical trend, $\mathrm{p}<0.10$, where the group with depression had multiple diagnoses and used more medications $(\mathrm{p}=0.09)$, had a lower maximum walking speed $(\mathrm{p}=0.08)$ and were less able to rise from chair independently $(\mathrm{p}=0.05)$ compared with the group without depression.

\section{DISCUSSION}

Nursing home residents with dementia are a heterogeneous group in terms of physical function and depression. By applying the recommended cut-off of $\geq 8$ on CSDD, $23.5 \%$ of the participants were classified as being depressed. Large differences in physical and mental health among institutional residents have also been underlined by other authors, ${ }^{194060}$ as well as the prevalence of depression in nursing home residents with dementia. ${ }^{691961}$ A Swedish study among persons aged 85 and over showed a $27 \%$ prevalence of depression in general but a $42 \%$ prevalence among those living in institutions. ${ }^{7}$ Studies have shown that depression among those in residential care is associated with decreased cognitive status, functional capacity, clinician-rated health ${ }^{62}$ and increased mortality. ${ }^{63}$ The common comorbidity of depression and dementia further increases risks of functional disability and nursing home admissions. ${ }^{64}$

Our results revealed significant associations between higher scores on the CSDD, indicating more symptoms of depression, and lower scores on BBS $(\mathrm{p}=0.006)$, $30 \mathrm{~s}$ CST $(\mathrm{p}=0.001)$ as well as maximum walking speed $(\mathrm{p}=0.003)$, indicating lower level of physical function. This corresponds well with the notion that high level of physical activity is associated with preservation of physical function in daily life ${ }^{22} 2765-67$ and a low prevalence of depressive symptoms. ${ }^{16}{ }^{17}$ Furthermore, with the exception of walking speed, the differences in physical function remained significant between the groups classified as depressed (CSDD $\geq 8$ ) and not depressed (CSDD $<8$ ) in the logistic regression analyses. The findings confirmed our assumption that depression and depressive symptoms among nursing home residents with dementia are significantly associated with functional performance.

Our findings regarding age, gender and duration of stay in nursing home corresponded well with results from similar studies and reports among nursing home residents. ${ }^{40}{ }^{68-71}$ Depression is a complex phenomenon in terms of causes and symptoms. ${ }^{72}$ The adjusted determination coefficient was low, and approximately the same, in all three models (table 3 ), indicating that depression is a complex phenomenon. Overall, our results underline the fact that depression has many explanatory mechanisms. Physical function alone cannot explain depression, although there are significant associations. ${ }^{73}$

We found no significant associations between ADL function and depression, which is in line with the study of Barca and colleagues ${ }^{9}$ and in contrast to other studies. ${ }^{829}$ However, BI is a proxy-reported measurement and may not be sensitive enough to identify the true abilities of an individual. ${ }^{30}$ The readiness of the nursing home staff to assist as well as the institutionalisation of the residents may influence the scores on BI. Our study showed no significant associations between depression and the degree of 


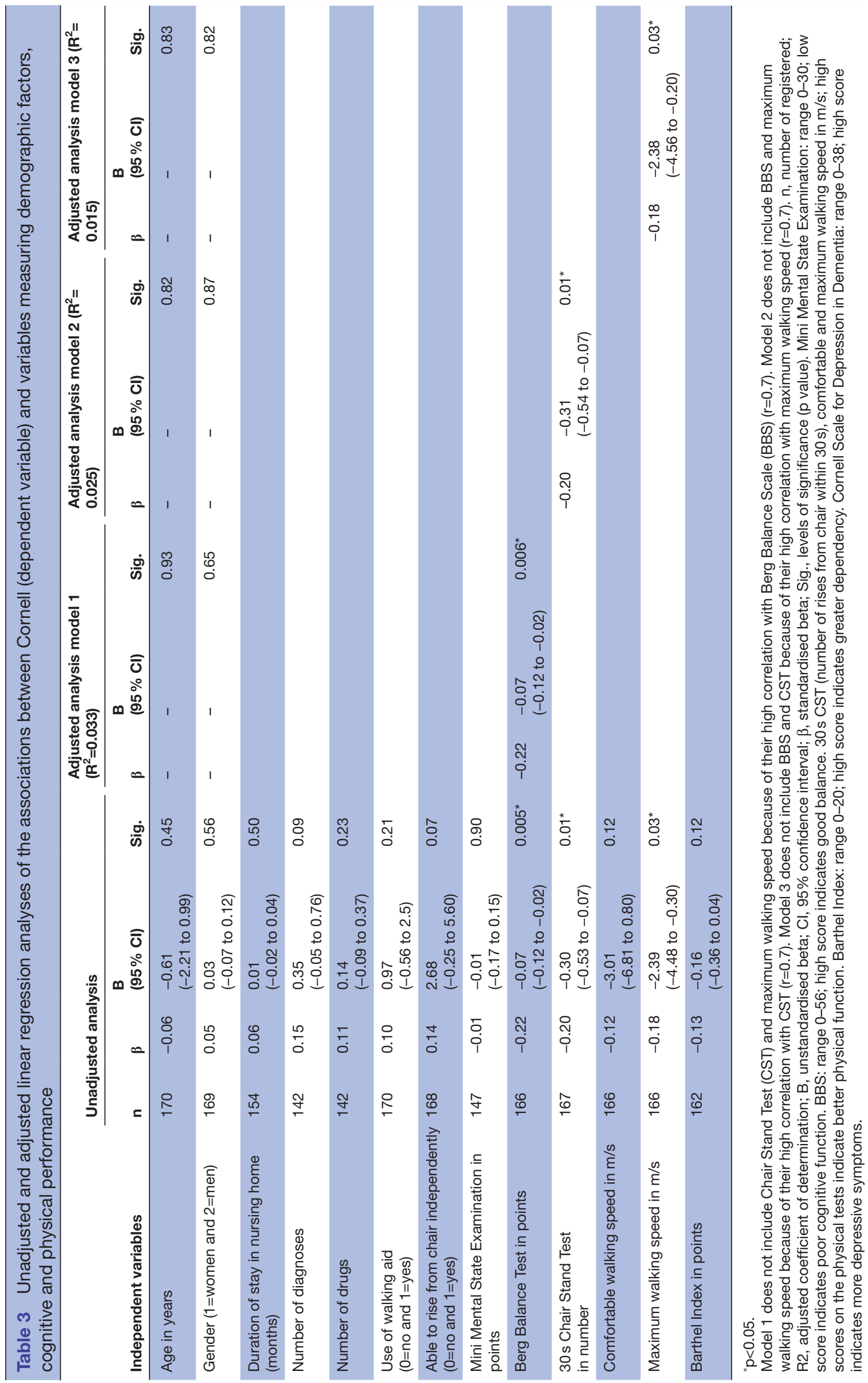

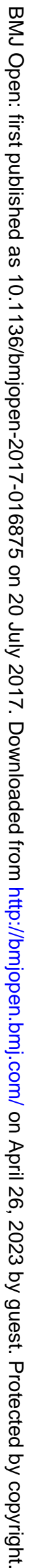




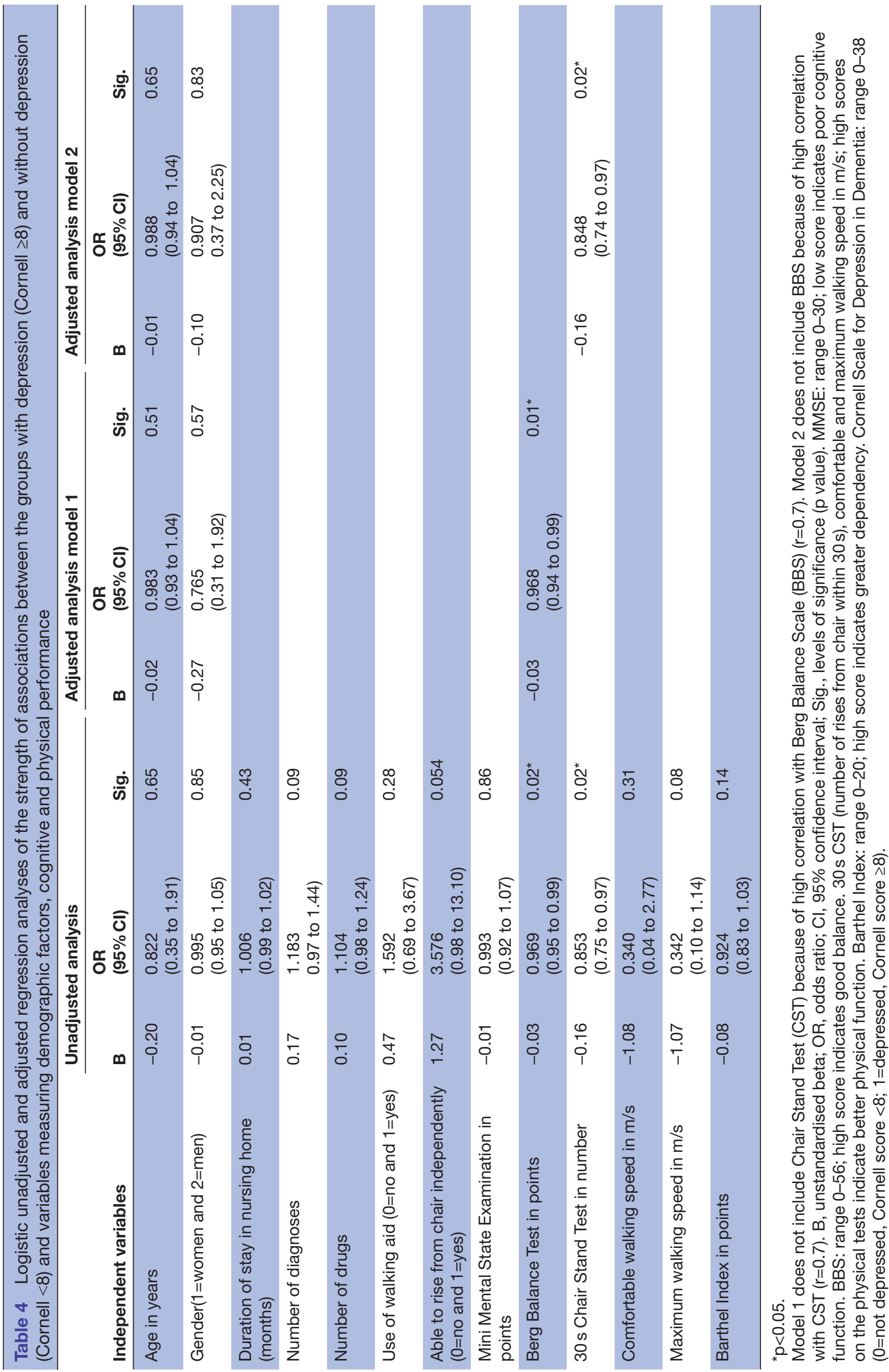

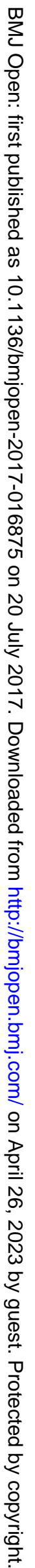


cognitive impairment. This is in line with another study that included participants with dementia, ${ }^{74}$ but it is inconsistent with results from a study that included both cognitively intact and residents with dementia. ${ }^{9}$

Several factors can influence physical function. Psychotropic medications, benzodiazepines or antipsychotic medications may affect balance and physical functioning. Inactivity, the precursor for reduced physical function, can be a direct result of depression as common symptoms are lack of interest in activities and loss of energy. ${ }^{6} 812$ Unfortunately, there are no available data on the types of medications that the participating residents used. The category 'chronic disorders' embraces musculoskeletal diagnoses, cardiovascular disorders, psychiatric diagnoses and comorbid neurological conditions such as epilepsy, stroke and Parkinson's Disease. These are all disorders that can affect balance and physical function. However, there were no significant differences between the group of depressed and not depressed regarding musculoskeletal, neurological or cardiovascular diagnoses. Depressed participants had significantly more psychiatric diagnoses than the not depressed $(\mathrm{p}=0.02)$, which were expected considering depression was included in this category.

When more than one statistical test is conducted in analysing data from clinical studies, some demand that a more stringent criterion should be used for statistical significance than the conventional $\mathrm{p}<0.05$. However, according to Perneger and coworkers, adjustments for multiple tests (Bonferroni adjustments) create more problems than they solve. They state that simply describing what tests of significance that have been performed, and why, is generally the best way of dealing with multiple comparisons. ${ }^{75}$ Although we have conducted several tests, we have therefore not performed adjustments for statistical significance (the Bonferroni method) but recommend reflective and cautious interpretation of the results. There are some variables missing from the dataset. Regarding the physical tests, the main reason for this is the fact that the residents were not available in the testing moment on the specific day. Some residents were not capable of performing the MMSE test because of hearing and vision impairment. The MMSE measurement is sensitive to factors like education level, age, sensory impairment, literacy problems, lack of motivation, impaired vision and hearing and depressive disorders. ${ }^{56}$ These factors may also explain the lack of correlation with depression in this study.

\section{Strength and limitations of the study}

The study included a well-defined population of older nursing homes residents with mild and moderate dementia defined by a score of 1 or 2 on the CDR Scale. ${ }^{35}$ The inclusion criteria made it possible to include participants with a broad range of mental and functional capacities. In addition, the study population seems to represent nursing home residents with respect to age and gender, which is a further strength. ${ }^{40}{ }^{69}$ Measuring instruments employed in this study are standardised and commonly used in clinical practice among frail elderly in nursing homes.

The present study has several limitations. The participants were enrolled in a physical exercise intervention trail (EXDEM), so they were likely to be fitter and maybe more motivated than those who would not have agreed to be part of the intervention. In addition, due to safety and the importance of the participants receiving instruction during exercise, the residents with severe communication problems were excluded. Because of this, the associations revealed in this study may not be applicable to the overall population of nursing home residents with dementia. Many of the participants in our study did not have a prior dementia diagnosis. All the residents had been assessed by CDR, a commonly used instrument in nursing homes. It is important to underline that one single instrument is not as accurate as a clinical diagnosis, which implies the possibility that some participants may have been wrongly diagnosed with dementia. ${ }^{76}$ However, the CDR score have been found to be in agreement with the golden standard of dementia diagnosis. ${ }^{77}$ According to score on CDR, all the residents had mild and moderate dementia. However, on MMSE, $11 \%$ scored lower than 10 points, which may indicate severe dementia. This means that 16 participants may have been wrongly categorised with mild/moderate dementia, which may have influenced the results. Drugs and diagnoses were to be reported in the case report. Regretfully, some of the designated healthcare workers failed to complete the case report. This resulted in lacking information about drugs and diagnoses in some cases, which could be of importance regarding the interpretation of the results. Because of the cross-sectional design of the study, we cannot draw conclusions about causality.

Despite the limitations, the study represent important information about associations between depression and physical function in a population of elderly nursing home residents with mild to moderate dementia.

\section{CONCLUSION}

Our study has shown that nursing home residents with good physical function (balance, muscle strength and walking speed) experienced less depressive symptoms. Depression is complex and a multicausal disorder. However, the implications of this study emphasise that physical activity is important for maintaining physical function for this vulnerable group and should at least be part of an intervention to improve depressive symptoms. Further studies should investigate possible methods on how to motivate nursing home residents to participate in physical activity and how health workers in nursing home might contribute to improve physical functioning and hence possibly decrease depressive symptoms in nursing home residents. The potential interaction of dementia with poor physical function and depression indicates an area to explore 
in future epidemiological studies with a prospective design.

Twitter Follow Linda Kvæl at @lindakvael.

Contributors LAHK, AB and EWT participated in contribution to the design of the study, accountability for all aspects of the work and approval of the published version. LAHK was involved in drafting of the work. $A B$ and EWT were responsible for revising the work.

Funding The Norwegian Fund for Post-Graduate Training in Physiotherapy funded this work, and the support of this organisation is gratefully acknowledged. The Norwegian Extra Foundation for Health and Rehabilitation has made the original project possible.

\section{Competing interests None declared.}

Patient consent Detail has been removed from this case description/these case descriptions to ensure anonymity. The editors and reviewers have seen the detailed information available and are satisfied that the information backs up the case the authors are making.

Ethics approval The study was approved by the Regional Committee for Medical Ethics in Norway, reference number: 2012/1150.

Provenance and peer review Not commissioned; externally peer reviewed.

Data sharing statement No additional data are available.

Open Access This is an Open Access article distributed in accordance with the Creative Commons Attribution Non Commercial (CC BY-NC 4.0) license, which permits others to distribute, remix, adapt, build upon this work non-commercially, and license their derivative works on different terms, provided the original work is properly cited and the use is non-commercial. See: http://creativecommons.org/ licenses/by-nc/4.0/

(c) Article author(s) (or their employer(s) unless otherwise stated in the text of the article) 2017. All rights reserved. No commercial use is permitted unless otherwise expressly granted.

\section{REFERENCES}

1. Prince M, Bryce R, Albanese E, et al. The global prevalence of dementia: a systematic review and metaanalysis. Alzheimers Dement 2013;9:63-75.

2. Seitz D, Purandare N, Conn D. Prevalence of psychiatric disorders among older adults in long-term care homes: a systematic review. Int Psychogeriatr 2010;22:1025-39.

3. Lithgow S, Jackson GA, Browne D. Estimating the prevalence of dementia: cognitive screening in Glasgow nursing homes. Int $J$ Geriatr Psychiatry 2012;27:785-91.

4. Cheng ST, Lam LC, Chow PK. Under-recognition of dementia in long-term care homes in Hong Kong. Aging Ment Health 2012;16:516-20.

5. Cherubini A, Ruggiero C, Dell'Aquila G, et al. Underrecognition and undertreatment of dementia in Italian nursing homes. J Am Med Dir Assoc 2012;13:759.e7-759.e13.

6. Selbaek G, Kirkevold $\varnothing$, Engedal K. The prevalence of psychiatric symptoms and behavioural disturbances and the use of psychotropic drugs in Norwegian nursing homes. Int J Geriatr Psychiatry 2007;22:843-9.

7. Bergdahl E, Allard P, Gustafson Y. Depression among the very old with dementia. Int Psychogeriatr 2011;23:756-63.

8. Mjørud M, Engedal K, Ytrehus S, et al. Livskvalitet, depressive symptomer og funksjonssvikt hos personer med demens. Sykepleien Forskning 2011;6:176-84.

9. Barca ML, Selbaek G, Laks J, et al. Factors associated with depression in Norwegian nursing homes. Int J Geriatr Psychiatry 2009;24:417-25

10. World Health Organization. [Online] Health Topics, Depression. www. who.int/topics/depression/en/ (accessed 25 Mar 2016).

11. Djernes JK. Prevalence and predictors of depression in populations of elderly: a review. Acta Psychiatr Scand 2006;113:372-87.

12. Jongenelis K, Pot AM, Eisses AM, et al. Prevalence and risk indicators of depression in elderly nursing home patients: the AGED study. J Affect Disord 2004;83(2-3):135-42.

13. Djernes JK, Gulmann NC, Foldager L, et al. 13 year follow up of morbidity, mortality and use of health services among elderly depressed patients and general elderly populations. Aust N Z J Psychiatry 2011;45:654-62.
14. Kitwood T. Understanding senile dementia: a psychobiographical approach. Free Associations 1990;19:60-75.

15. World Health Organization. [Online] Media Centre, Depression, fact sheets. http://www.who.int/mediacentre/factsheets/fs369/en/ (accessed 25 Mar 2016)

16. Fukukawa Y, Nakashima C, Tsuboi S, et al. Age differences in the effect of physical activity on depressive symptoms. Psychol Aging 2004;19:346-51.

17. Barbour KA, Edenfield TM, Blumenthal JA. Exercise as a treatment for depression and other psychiatric disorders: a review. $J$ Cardiopulm Rehabil Prev 2007;27:359-67.

18. Windle $G$, Hughes $D$, Linck $P$, et al. Is exercise effective in promoting mental well-being in older age? A systematic review. Aging Ment Health 2010;14:652-69.

19. Telenius EW, Engedal K, Bergland A. Physical performance and quality of life of nursing-home residents with mild and moderate dementia. Int J Environ Res Public Health 2013;10:6672-86.

20. Kolanowski A, Buettner L, Litaker M, et al. Factors that relate to activity engagement in nursing home residents. Am J Alzheimers Dis Other Demen 2006;21:15-22.

21. Forbes D, Forbes SC, Blake CM, et al. [Online] Exercise programs for people with dementia (Review). Cochrane Library. 2015. http:// onlinelibrary.wiley.com/.

22. Singh MA. Exercise comes of age: rationale and recommendations for a geriatric exercise prescription. J Gerontol A Biol Sci Med Sci 2002;57:M262-M282.

23. Helbostad JL. [Physical training for nursing home residents-has it any effect?]. Tidsskr Nor Laegeforen 2005;125:1195-7.

24. Nelson ME, Rejeski WJ, Blair SN, et al. Physical activity and public health in older adults: recommendation from the American College of Sports Medicine and the American Heart Association. Med Sci Sports Exerc 2007;39:1435-45.

25. Rolland Y, Pillard F, Klapouszczak A, et al. Exercise program for nursing home residents with Alzheimer's disease: a 1-year randomized, controlled trial. J Am Geriatr Soc 2007;55:158-65.

26. Chodzko-Zajko WJ, Proctor DN, Fiatarone Singh MA, et al. American College of Sports Medicine position stand. Exercise and physical activity for older adults. Med Sci Sports Exerc 2009;41:1510-30.

27. Weening-Dijksterhuis E, de Greef MH, Scherder EJ, et al. Frail institutionalized older persons: a comprehensive review on physical exercise, physical fitness, activities of daily living, and quality-of-life. Am J Phys Med Rehabil 2011;90:156-68.

28. Grønstedt H. Individually tailored physical and daily activities for residents in nursing home settings: a scandinavian multi-centre study (Phd-thesis). Stockholm: Karolinska institutet, 2013.

29. Kaup BA, Loreck D, Gruber-Baldini AL, et al. Depression and its relationship to function and medical status, by dementia status, in nursing home admissions. Am J Geriatr Psychiatry 2007:15:438-42.

30. Brach JS, VanSwearingen JM, Newman AB, et al. Identifying early decline of physical function in community-dwelling older women: performance-based and self-report measures. Phys Ther 2002;82:320-8

31. Borza T, Engedal K, Bergh S, et al. The course of depressive symptoms as measured by the Cornell Scale for depression in dementia over 74 months in 1158 nursing home residents. J Affect Disord 2015;175:209-16.

32. Lolk A, Andersen K. Prevalence of depression and dementia among nursing home residents. Ugeskr Laeger 2015;177:11140591.

33. Lövheim H, Sandman PO, Kallin K, et al. Relationship between antipsychotic drug use and behavioral and psychological symptoms of dementia in old people with cognitive impairment living in geriatric care. Int Psychogeriatr 2006;18:713-26.

34. Olsen C, Pedersen I, Bergland A, et al. Effect of animal-assisted interventions on depression, agitation and quality of life in nursing home residents suffering from cognitive impairment or dementia: a cluster randomized controlled trial. Int $J$ Geriatr Psychiatry 2016;31:1312-21.

35. Hughes CP, Berg L, Danziger WL, et al. A new clinical scale for the staging of dementia. Br J Psychiatry 1982;140:566-72.

36. Alexopoulos GS, Abrams RC, Young RC, et al. Cornell Scale for Depression in Dementia. Biol Psychiatry 1988;23:271-84.

37. Barca ML, Selbaek G, Laks J, et al. The pattern of depressive symptoms and factor analysis of the Cornell Scale among patients in Norwegian nursing homes. Int J Geriatr Psychiatry 2008;23:1058-65.

38. Barca ML, Engedal K, Selbaek G. A reliability and validity study of the Cornell Scale among elderly inpatients, using various clinical criteria. Dement Geriatr Cogn Disord 2010;29:438-47.

39. Berg K, Wood-Dauphine S, Willims Jl, et al. Measuring balance in the elderly: preliminary development of an instrument. Physiotherapy Canada 1989:41:304-11. 
40. Bergland A, Narum I, Grønstedt $\mathrm{H}$, et al. Evaluating the feasibility and intercorrelation of measurements on the functioning of residents living in Scandinavian nursing homes. Phys Occup Ther Geriatr 2010;28:154-69.

41. Bogle Thorbahn LD, Newton RA. Use of the Berg Balance Test to predict falls in elderly persons. Phys Ther 1996;76:576-83.

42. Halsaa KE, Brovold T, Graver V, et al. Assessments of interrater reliability and internal consistency of the Norwegian version of the Berg Balance Scale. Arch Phys Med Rehabil 2007;88:94-8.

43. Telenius EW, Engedal K, Bergland A. [Online] Inter-rater reliability of the Berg Balance Scale, 30s chair stands test and $6 \mathrm{~m}$ walking test, and construct validity of the Berg Balance Scale in nursing home residents with mild-to-moderate dementia. BMJ Open Rehabilitation Medicine 2015;5

44. Conradsson M, Lundin-Olsson L, Lindelöf N, et al. Berg balance scale: intrarater test-retest reliability among older people dependent in activities of daily living and living in residential care facilities. Phys Ther 2007;87:1155-63.

45. Rikli R, Jones CJ. Senior Fitness Test Manual. Second edition. Copenhagen: FADL's forlag, 2013.

46. Telenius EW, Engedal K, Bergland A. Effect of a high-intensity exercise program on physical function and mental health in nursing home residents with dementia: an assessor blinded randomized controlled trial. PLoS One 2015;10:e0126102.

47. Csuka M, McCarty DJ. Simple method for measurement of lower extremity muscle strength. Am J Med 1985;78:77-81.

48. Goldberg A, Chavis M, Watkins J, et al. The five-times-sit-to-stand test: validity, reliability and detectable change in older females. Aging Clin Exp Res 2012;24:339-44.

49. Studenski S, Perera S, Wallace D, et al. Physical performance measures in the clinical setting. J Am Geriatr Soc 2003;51:314-22.

50. Peel NM, Kuys SS, Klein K. Gait speed as a measure in geriatric assessment in clinical settings: a systematic review. J Gerontol A Biol Sci Med Sci 2013;68:39-46.

51. Mahoney FI, Barthel DW. Functional evaluation: the Barthel index. Md State Med J 1965;14:61-5.

52. Collin C, Wade DT, Davies S, et al. The Barthel ADL Index: a reliability study. Int Disabil Stud 1988;10:61-3.

53. Engedal K, Haugen PK. The prevalence of dementia in a sample of elderly norwegians. Int J Geriatr Psychiatry 1993;8:565-70.

54. Nygaard HA, Ruths S. Missing the diagnosis: senile dementia in patients admitted to nursing homes. Scand J Prim Health Care 2003;21:148-52.

55. Folstein MF, Folstein SE, McHugh PR. "Mini-mental state". A practical method for grading the cognitive state of patients for the clinician. J Psychiatr Res 1975;12:189-98.

56. Strobel C, Engedal KM-NR. Norsk Revidert Mini Mental Status Evaluering. Revidert og utvidet manual. Oslo: Nasjonalt Kompetansesenter for Aldring og Helse, 2008.

57. Pallant J. SPSS Survival manual. A step by step quide to data analysis using SPSS. 4 th edition: Allen \& Unwin Book Publisher, 2010.

58. Hoaglin DC, Iglewicz B, Tukey JW. Performance of some resistant rules for outlier labeling. J Am Stat Assoc 1986;81:991-9.
59. Kukull WA, Larson EB, Teri L, et al. The Mini-Mental State Examination score and the clinical diagnosis of dementia. J Clin Epidemiol 1994;47:1061-7.

60. Frändin $\mathrm{K}$, Borell L, Grönstedt $\mathrm{H}$, et al. A nordic multi-center study on physical and daily activities for residents in nursing home settings: design of a randomized, controlled trial. Aging Clin Exp Res 2009;21:314-22.

61. Rosenvinge $\mathrm{BH}$, Rosenvinge $\mathrm{JH}$. Occurrence of depression in the elderly - a systematic review of 55 prevalence studies from 19902001. Tidsskr Nor Laegeforen 2003;123:928-9.

62. Katz IR, Simpson GM, Curlik SM, et al. Pharmacologic treatment of major depression for elderly patients in residential care settings. $J$ Clin Psychiatry 1990;51:41-8.

63. Rovner BW, German PS, Brant LJ, et al. Depression and mortality in nursing homes. JAMA 1991;265:993-6.

64. Kales HC, Chen P, Blow FC, et al. Rates of clinical depression diagnosis, functional impairment, and nursing home placement in coexisting dementia and depression. Am J Geriatr Psychiatry 2005;13:441-9.

65. Heyn P, Abreu BC, Ottenbacher KJ. The effects of exercise training on elderly persons with cognitive impairment and dementia: a metaanalysis. Arch Phys Med Rehabil 2004;85:1694-704.

66. Chin A Paw MJ, van Uffelen JG, Riphagen I, et al. The functional effects of physical exercise training in frail older people : a systematic review. Sports Med 2008;38:781-93.

67. Forster A, Lambley R, Hardy J, et al. [Online] Rehabilitation for older people in long-term care (Review). Cochrane Database Syst Rev 2009;21:1.

68. Wolter LL, Studenski SA. A clinical synthesis of falls intervention trials. Top Geriatr Rehabil 1996;11:9-19.

69. Barca ML, Engedal K, Laks J, et al. Quality of life among elderly patients with dementia in institutions. Dement Geriatr Cogn Disord 2011;31:435-42.

70. Grönstedt $H$, Hellström K, Bergland A, et al. Functional level, physical activity and wellbeing in nursing home residents in three Nordic countries. Aging Clin Exp Res 2011;23:413-20.

71. Sentralbyrå S. Eldres bruk av helse- og omsorgstjenester. Oslo: Ramm, J (red), 2013.

72. Iden KR. Depresjon i sykehjem - underdiagnostikk og overbehandling: Avhandling for graden philosophiae doctor (PhD): Universitetet i Bergen, 2015.

73. Bjørndal A, Hofoss D. Statistikk for helse- og sosialfagene. Oslo: Gyldendal Akademisk, 2010.

74. Verkaik R, Nuyen J, Schellevis F, et al. The relationship between severity of Alzheimer's disease and prevalence of comorbid depressive symptoms and depression: a systematic review. Int $J$ Geriatr Psychiatry 2007;22:1063-86.

75. Perneger TV. What's wrong with Bonferroni adjustments. BMJ 1998;316:1236-8.

76. Palm R, Jünger $\mathrm{S}$, Reuther $\mathrm{S}$, et al. People with dementia in nursing home research: a methodological review of the definition and identification of the study population. BMC Geriatr 2016;16:78.

77. Chaves ML, Camozzato AL, Godinho C, et al. Validity of the clinical dementia rating scale for the detection and staging of dementia in Brazilian patients. Alzheimer Dis Assoc Disord 2007;21:210-7. 